\title{
PROGRAMAS EDUCATIVOS EM MUSEUS: UM ESTUDO DE CASO
}

\author{
Anamaria Aziz Cretton ${ }^{\text {** }}$ \\ Centro Nacional de Folclore e Cultura Popular \\ Diana de Souza Pinto ${ }^{2 * *}$ \\ Universidade Federal do Estado do Rio de Janeiro
}

RESUMO:

Este artigo discute as práticas comunicativas institucionais co-construídas pelo Centro Nacional de Folclore e Cultura Popular (CNFCP) e por uma escola Municipal do Rio de Janeiro com base em um estudo de caso de natureza etnográfica.A análise do corpus suscita reflexões sobre questões conceituais relativas às noções de folclore e cultura popular, segundo as diferentes perspectivas de ambas as instituições. Argumenta-se em favor do reconhecimento das ações educativas em museus e da necessidade de maior interação/ mediação entre os campos da museologia e da educação.

\section{PALAVRAS-CHAVES:}

Museu, Educação, Práticas comunicativas institucionais, Mediação, Folclore, Cultura popular.

\section{Educational Programs in Museums: a case study}

\begin{abstract}
:
The aim of this paper is to discuss the institutional communication practices jointly constructed by the National Center of Popular Culture (CNFCP) and a public school located in the city of Rio de Janeiro, Brazil, based on an ethnographic case study. The corpus analysis suggests conceptual issues related to folklore and popular culture according to the different perspectives of each institution. Arguments are presented in favor of recognizing the existence of educational initiatives in museums and the need for greater interaction/mediation between the fields of museology and education.
\end{abstract}

\section{KEYWORDS:}

Museum, Education, Communicative Institutional Practices, Mediation, Folklore, Popular culture.

\footnotetext{
I * Mestre em Memória Social pelo Programa de Pós-Graduação da UNIRIO, com especialização em Literatura Infanto juvenil, pela Universidade Federal Fluminense (UFF) e em Leitura: teoria e prática, pela UniverCidade. Atuou em projetos de leitura e contadores de histórias junto ao PROLER (Programa Nacional de Incentivo à Leitura), LerUERJ (Programa de Leitura da UERJ) e ao Leia Brasil (Petrobras); é integrante do "Confabulando contadores de histórias" desde sua fundação em 1994. Foi professora em escolas particulares do Rio de Janeiro e do Instituto de Artes da UERJ. Atualmente trabalha no Programa Educativo do Centro Nacional de Folclore e Cultura Popular.

$2^{* *}$ Possui graduação em Letras pela PUC-RJ, mestrado em Linguística Aplicada e doutorado em Psiquiatria, Psicanálise e Saúde Mental, ambos pela UFRJ. É professora da UNIRIO, atuando no Programa de Pós-Graduação em Memória Social.Tem experiência na área de Linguística, com ênfase em Análise do Discurso sob a perspectiva sócio-interacionista, atuando, principalmente, nos seguintes temas: narrativas, práticas comunicativas institucionais, e memória social.
} 
Para escrever este artigo, tomamos por base uma pesquisa realizada no Programa de Pós-Graduação em Memória Social da UNIRIO3. O estudo se insere no campo de investigação que visa a examinar as ações educativas desenvolvidas no âmbito de centros culturais considerando-as como ações mediadoras entre essas instituições e o público escolar (GOUVÊA; MARANDINO; LEAL, 2003; SANTOS, 2008). Apesar de existir um número significativo de estudos nessa área ${ }^{4}$, é um campo que carece de avaliações sistemáticas permanentes e, portanto, fértil para investigações científicas. Para introduzirmos o tema da educação em museus, será necessário traçarmos uma breve historiografia sobre as instituições museais, apontando alguns marcos que fundamentam ampliações conceituais e a necessidade de diálogo entre os dois diferentes campos do conhecimento: educação e museologia.

A aproximação entre museu e escola teve início na França e na Inglaterra, no fim do século XIX e início do XX. O motivo que leva os serviços educativos em museus a privilegiarem o público escolar justifica-se pela constatação de que $90 \%$ dos visitantes se constitui por estudantes. $\mathrm{Na}$ década de 1930, a divulgação científica encontra, na instituição museal, um dos seus canais de difusão e comunicação com o público escolar e, ao mesmo tempo, justifica sua função social. De fato, os museus de ciência são os museus que investem com maior expressividade em programas educativos e são também contemplados por um número maior de estudos de avaliação de suas ações educativas.

O International Council of Museums (ICOM), vinculado à UNESCO, promoveu em 1952, em Nova York, um seminário sobre o papel dos museus na educação, reunindo educadores e técnicos. Nessa ocasião, algumas resoluções foram tiradas indicando a necessidade de maior integração entre o trabalho educativo dos museus e os currículos escolares e, ainda, a necessidade de incluir um treinamento sobre a utilização dos museus na formação de professores.

Mudanças importantes se concretizaram a partir das décadas de 1970 e 1980. O Movimento Internacional da Nova Museologia (MINOM) teve como base dois encontros significativos dentro da historiografia museológica: a mesa redonda que gerou a Declaração de Santiago (1972) e o ateliê internacional no Canadá que gerou a retomada explícita desse documento na Declaração de Quebec (1984).A partir daí duas concepções importantes apontam para mudanças paradigmáticas: a noção de "museu integral”, que interage com "a totalidade dos problemas da sociedade, e a de museu como ação, como instrumento dinâmico de mudança social" (STUDART, 2004, p. 42). Além de pesquisar, conservar e expor acervos, a função comunicativa dos museus e, portanto, as preocupações com o visitante e as interações com este público passaram a merecer atenção especial.

Museólogos brasileiros, ao longo do século $X X$, vêm participando de reflexões sobre o seu fazer profissional no campo das ações educativas através de encontros, discussões e publicações importantes para o campo da museologia no país. Temos notícias de serviços educativos desenvolvidos no

3 Esse artigo integra a dissertação de mestrado em Memória Social da UNIRIO, intitulada "Folclore, cultura popular e educação: discursos e memórias em práticas comunicativas institucionais" (CRETTON, 2009). A pesquisa recebeu o apoio da CAPES.

4 Sobre o assunto, ver bibliografia selecionada pelo CECA-Brasil na revista MUSAS I (CHAGAS, 2004, p. 65-84). 
Brasil, já na década de 1920 e 30, introduzidos por Edgar Roquette Pinto, então diretor do Museu Nacional. Bertha Lutz, funcionária dessa instituição, após visitar 58 museus na América do Norte, em 1932, escreveu um relatório intitulado:"O papel educativo do Museu Moderno" no qual ressalta a importância de "um dos temas que ainda se reveste da maior atualidade para a museologia no Brasil: os estudos de público". Essa experiência fazia parte de um curso de aperfeiçoamento no qual Bertha Lutz estudou "os departamentos e serviços educativos mantidos por essas instituições” (LOPES, 2006, p. 4I-47).

Entre os 29 comitês internacionais do ICOM, cabe-nos destacar o CECA (Committee for Education and Cultural Action) que objetiva promover "o intercâmbio de informações e ideias sobre a teoria e a prática da educação em museus". O CECA-Brasil organizou-se em 1995 e, desde então,"vem preparando, anualmente, textos reflexivos sobre os temas das conferências anuais do CECA" (STUDART, 2004, p. I2-I4). Na tentativa de interpretar os temas desses encontros, percebemos que a preocupação com o público, a busca de estratégias de comunicação e a articulação com questões sociais e culturais representam um esforço, dos profissionais envolvidos nesse comitê, em refletir sobre o papel educativo dos museus. Cabe-nos aqui perguntar de que concepção de educação estamos falando. Studart, que assumiu a coordenação do CECA-Brasil em 200I, expõe a perspectiva contemporânea:"chamamos a atenção para a importância de conceber as ações educativas como processo, em que a tônica seja o diálogo, a troca e a construção conjunta do conhecimento" (STUDART, 2004, p. 38). Para a autora, o objetivo da educação, em seu sentido amplo,"é oferecer possibilidades para a comunicação, a informação, o aprendizado, a relação dialética e dialógica educando/educador" (STUDART, 2004, p. 37).

Contudo, nem sempre o trabalho prático reitera esses princípios, pois diferentes concepções de educação norteiam ações educativas em museus desde que se tem notícia desses programas. Como destaca Chagas (1996, p. 83):

muitas vezes o discurso tem caminhado num sentido e a prática em outro; [...] com o modismo do labor educativo, [os museus] optam por um trabalho qualquer (grifos do autor), não levando em consideração o seu poder de interferência e transformação da realidade [...].

O autor defende um "museu participativo" no qual as ações educativas sejam desenvolvidas a partir de objetivos claros e de forma criativa e sistemática. Critica as práticas da "ação pela ação" que "tendem à criação de fossos separando o público do acervo" (CHAGAS, 1996, p. 83).

Santos (2008, p. 128) destaca que, nas ações educativas em museus, além de clareza sobre as concepções de educação e de museologia "adotadas pelos sujeitos sociais envolvidos", os projetos precisam também ser flexíveis aos diferentes contextos e expectativas em que estão inseridos e acompanhados por "um processo constante de ação e de reflexão, no qual teoria e prática estejam sempre em interação.

Além de propor essa auto avaliação permanente, Santos (2008, p. I32133) traz a baila outra questão pertinente e inquietante: para a maior parte do público escolar o museu "ainda permanece como 'um local onde se guarda coisas antigas', sendo que o patrimônio cultural é compreendido como algo que se esgota no passado, [...] sem nenhuma relação com a vida, no presente". Essa leitura da instituição museal instaurou-se em nossa memória, constituindo-nos e trazendo consequências ainda mais complexas. "Cultura, patrimônio 
e tradição são produtos dissociados do cotidiano do professor e da vida dos seus alunos" (SANTOS, 2008, p. I32-I33).

Compreender a maneira como a escola concebe as categorias museu e patrimônio cultural é fundamental para o exame e avaliação das ações educativas nas instituições museais. $O$ que foi que o museu fez, ou deixou de fazer, para a construção dessa memória? Se o objetivo é aproximar museus e público escolar, que estratégias são realizadas nesse sentido? Quais seriam os avanços observados?

\section{Apresentando o estudo de caso}

A pesquisa que fundamenta este artigo foi construída a partir de um estudo de caso, de natureza etnográfica, com o objetivo de observar, acompanhar e examinar a operacionalização de uma das ações do programa educativo do Centro Nacional de Folclore e Cultura Popular (CNFCP) realizada em uma determinada escola municipal da cidade do Rio de Janeiro, situada na zona da Leopoldina, a fim de analisar essa prática comunicativa institucional ${ }^{5}$.

O CNFCP pesquisa, documenta, divulga e apoia "as expressões da cultura popular brasileira, reunindo ao longo dos anos, um rico acervo museológico, bibliográfico, sonoro e visual", sendo uma referência nacional em sua especialidade, conforme a brochura de divulgação da instituição. Para a realização deste estudo, selecionamos o projeto itinerante "De mala e cuia", uma pequena coleção do acervo institucional que oferece, através de empréstimos, um material diversificado sobre folclore e cultura popular. A coleção é composta por livros, catálogos, xilogravuras, folhetos de cordel, artigos de jornal, CDs, DVDs e fotos, selecionados a partir da constatação das dificuldades da pesquisa escolar. É uma das ações educativas que o CNFCP desenvolve e com as quais objetiva aproximar o público escolar do Museu de Folclore Edison Carneiro (MFEC) e do universo da cultura popular, buscando parcerias com professores, investindo na qualificação desses profissionais de ensino.

Tal projeto está em consonância com a sugestão de Santos (2008). De acordo com a autora, para motivação e estímulo da prática museológica educativa, é de fundamental importância "interagir com outras instituições, com os sujeitos sociais que estão fora do museu, 'sair da gaiola' [...]". Para ela, "há imensas possibilidades de crescimento da Museologia, do museu e da educação quando nos dispomos a aplicar ações museológicas fora dos espaços do museu" (SANTOS, 2008, p. 142).

Examinar e analisar tais ações educativas, enquanto estratégias de aproximação entre o público e os acervos institucionais, entre o público escolar e as questões temáticas da cultura popular motivam esta pesquisa. Algumas indagações norteiam nosso percurso: em que medida essas ações educativas, ao salientarem a diversidade cultural do folclore nacional, contribuem para a ampliação da memória nacional relativa ao nosso folclore? Que desdobramentos são possíveis, através dos empréstimos dessas coleções? Qual o seu alcance, enquanto instrumento de trabalho, para problematizar questões relevantes tais como a pluralidade das manifestações culturais e a importância da

5 A noção de 'prática comunicativa institucional' pressupõe que os agentes sociais em contextos institucionais se comunicam visando certos objetivos, convencionalmente vinculados à instituição em questão. São interações que podem envolver restrições especiais, estruturas e procedimentos particulares (DREW; HERITAGE, 1992). 
diversidade cultural? E, mais concretamente, como as ações educativas propostas pelo CNFCP foram operacionalizadas na Escola Municipal Coralina'?

Com este estudo de caso, que investiga o processo de empréstimo do projeto "De mala e cuia" nessa instituição escolar, procuramos responder à questão principal desta pesquisa: em que medida as ações examinadas reiteram e perpetuam discursos/memórias cristalizados a respeito do folclore e da cultura popular e/ou modificam e atualizam a abordagem desses temas, problematizando a pluralidade cultural brasileira no âmbito escolar? Porém, tratarmos do CNFCP implica considerar sua construção à luz do "movimento folclórico brasileiro" (VILHENA, 1997), o que será discutido a seguir.

\section{Memória do Folclore nas escolas}

A institucionalização dos estudos de folclore foi uma conquista do movimento folclórico brasileiro enquanto que sua marginalização das universidades foi resultante de lutas e disputas, no campo das Ciências Sociais. Mesmo não alcançando o estatuto de disciplina científica, conforme pretendido, o movimento gerou institutos, museus, bibliotecas e órgãos públicos que transformaram sua prática em instituições.

Por outro lado, a institucionalização de uma memória cultural do folclore associado à identidade nacional, ao passado, ao rural, "autêntico", “puro", "tradicional", coletivo e anônimo, e outras heranças do movimento folclórico, permanecem fortemente presentes nas escolas que, por sua vez, aderiram ou absorveram a perspectiva conceitual e metodológica da Comissão Nacional de Folclore e da Campanha de Defesa do Folclore Brasileiro, do final dos anos 40 a meados dos anos 60. A Comissão Nacional de Folclore (CNFL) foi fundada em 1947, como fruto do movimento folclórico brasileiro, vinculada ao Instituto Brasileiro de Educação, Ciência e Cultura e à UNESCO. Em 1958 a CNFL institui a Campanha de Defesa de Folclore Brasileiro (CDFB) vinculada ao então Ministério da Educação e Cultura. Em 1980, a Campanha (CDFB) foi incorporada à Funarte com o nome de Instituto Nacional de Folclore (INF) que, em 199I, passa a se chamar Coordenação de Folclore e Cultura Popular (CFCP). Em 1997, ocorre a reestruturação da Funarte, e a Coordenação (CFCP) se constitui no atual Centro Nacional de Folclore e Cultura Popular, vinculado desde 2003 ao Instituto do Patrimônio Histórico e Artístico Nacional (IPHAN) do Ministério da Cultura.

O desafio, portanto, que se impõe à equipe de educadores do CNFCP, ao reaproximar-se do campo da antropologia no contexto contemporâneo, é de ampliar os conceitos de folclore e cultura popular entre os profissionais de ensino, preocupação presente nas ações educativas da instituição, conforme consta em suas propostas. As ações educativas, ali desenvolvidas, são planejadas a partir de certas demandas observadas pela equipe, no contato com as escolas que frequentam a instituição visitando as exposições ou fazendo pesquisa na biblioteca.

A nova concepção antropológica reconhece o caráter dinâmico e processual da cultura e da construção de identidades. Por um lado, a perspectiva antropológica promoveu, na instituição cultural, uma mudança de paradigmas e uma revisão do olhar saudosista e nostálgico sobre o folclore, como um

6 Nome fictício da escola municipal na qual foi feita a pesquisa etnográfica, de acordo com a aprovação do projeto pelo Comitê de Ética da UNIRIO. 
objeto evanescente que precisa ser preservado: “o importante, então, diferentemente da perspectiva do folclorista, não seria buscar o que não muda; mas por que muda, como muda e interage com a modernidade" (ABREU, 2003, p. 93). Por outro lado, a instituição escolar continua trabalhando com as propostas da CDFB com relação às temáticas folclóricas, encaminhando pesquisas generalizadas, sem leitura crítica, caracterizando as manifestações culturais por adjetivos genéricos como 'típicas', 'regionais' 'tradicionais', 'anônimas' e 'pitorescas'.

Desse modo, investigar como as ações educativas, nesse contexto, são operacionalizadas também demanda, do pesquisador, a compreensão de que conceitos fundamentais, que as ancoram, são percebidos de maneiras distintas por ambas as instituições.

\section{A pesquisa no CNFCP e na Escola Municipal Coralina}

Desde o início da pesquisa, o Centro se mostrou interessado na investigação. A entrada na Escola Municipal Coralina foi facilitada pelo aval institucional do CNFCP.A escola onde foi feito o trabalho de campo situa-se no bairro de Bonsucesso, zona Norte do município do Rio de Janeiro e integra a zona da Leopoldina.

Acompanhamos o período de empréstimo na escola coletando um conjunto de dados: observações etnográficas do cotidiano escolar (cerca de 75 horas); fotografias de murais e demais trabalhos confeccionados pelos alunos durante o período de empréstimo do citado projeto; 23 entrevistas estruturadas para identificação do perfil sócio demográfico de parte do corpo docente; sete entrevistas semiestruturadas com profissionais da escola e duas com representantes do CNFCP; registros feitos a partir da observação de reuniões no CNFCP entre profissionais desta instituição cultural e professores interessados em fazer o empréstimo dos projetos itinerantes e alguns documentos escritos. As entrevistas semiestruturadas foram gravadas em áudio e, posteriormente, transcritas. Questões relativas a concepções sobre folclore e cultura popular e sobre a própria operacionalização do empréstimo do projeto integram o roteiro dessas entrevistas, realizadas pela autora principal deste artigo.

Para que a escola esteja capacitada a solicitar o empréstimo dos projetos itinerantes do CNFCP, é necessário que, ao menos um representante da escola solicitante participe de uma reunião com a equipe da Difusão Cultural. Esse é um momento de interação importante nesse processo comunicativo institucional. Não há um roteiro fixo para essas reuniões, por parte do CNFCP, mas há uma organização prévia da equipe, quanto aos assuntos mais importantes a serem discutidos. Fala-se sobre o histórico da instituição, algumas questões conceituais, objetivos do programa educativo, os cuidados com o acervo, o inventário que acompanha os projetos, os textos teóricos para pesquisa e os cadernos de relatos de experiência. Percebemos, ainda, uma metodologia no modo como a conversa é encaminhada.As duas representantes institucionais entrevistadas referem-se a essa conversa como uma oportunidade de "provocar" a reflexão do professor a respeito do folclore e da cultura popular. Entretanto, alguns problemas de comunicação de natureza interinstitucional foram detectados. 


\section{Águas passadas ainda movem moinhos?}

A análise dos dados deste estudo interdisciplinar transita entre os estudos da memória social e o campo de estudos da linguagem, a partir da análise do discurso em uma perspectiva sócio interacional. Segundo esse arcabouço teórico, surgido na década de 1970, o discurso é resultado do trabalho conjunto entre falantes e ouvintes em uma interação face a face (GOFFMAN, 2002).

A ideia de "lançar algumas provocações" para estimular a conversa, com o objetivo de dialogar com os professores sobre folclore e cultura popular, é indicada como "a melhor maneira de atingi-los e levantar algumas coisas que deem caldo pra eles conversarem", segundo Telles (2007), coordenadora do programa educativo, que fala em nome da instituição ("a gente"), destacando a autoria coletiva dessa metodologia. Aliás, "provocar" é um verbo utilizado diversas vezes nas entrevistas das duas representantes do CNFCP, enquanto estratégia que visa a atingir certos objetivos:"A gente não é neutro.A gente quer mudar a forma de olhar, provocar outros olhares sobre a cultura popular".

A comparação das expectativas das representantes da instituição cultural, na realização desses encontros com professores e no preparo dos textos de apresentação dos projetos educativos itinerantes, com o discurso das professoras entrevistadas com relação a essas experiências, mostra-se muito produtiva para esta pesquisa. É comum que as escolas enviem um ou dois docentes para essas reuniões. No grupo de 23 professoras diretamente envolvidas com a operacionalização do projeto "De mala e cuia" na escola observada, Maria foi a única que participou da reunião no CNFCP. Em sua opinião, ter participado da reunião realmente provocou mudanças em seu esquema de conhecimento ${ }^{7}$ :

Autora I: Pra você, folclore e cultura popular são a mesma coisa ou existem diferenças?

Maria: Não, anteriormente, eu achava que o folclore era aquela prática antiga, que as pessoas tinham hábito de fazer. $E$ a cultura popular, o que a gente fazia no dia a dia.Agora, eu já entendo que é a mesma coisa, na minha opinião, é a mesma coisa.

Autora I: Hum hum

Maria: É o ontem e o hoje e o que pode ser amanhã. (risos)

Autora I: Mas alguma coisa fez você pensar dessa forma?

Maria: Fez, justamente essa reunião, essa maneira que ela [representante do CNFCP] colocou, eu acho que mudou a minha ideia. Eu sempre achei que era uma coisa importante pra não ser esquecida. Mas, da maneira que ela colocou, eu vi que, realmente, é uma coisa que você vai criando, né, não acaba. (SILVA, 2007)

A prof. ${ }^{a}$ Maria (SILVA, 2007) explicita o motivo que a fez repensar conceitualmente as categorias folclore e cultura popular:"essa reunião, essa maneira que ela [representante do CNFCP] colocou”. No entanto, a questão do repasse dos conteúdos tratados na reunião, para a escola, traz alguns indicativos complicadores para essa comunicação institucional. As professoras

7 A noção de 'esquemas de conhecimento' em interação baseia-se em experiências anteriores, memórias, crenças e valores, mas são suscetíveis a atualizações na dinâmica dos encontros sociais. Estão, portanto, em constante modificação em função das várias interações, com diversos interlocutores, de que participamos em nossas experiências interacionais diárias (TANNEN;WALLAT, 2002). 
entrevistadas localizam, na pessoa da coordenadora da escola, o informe da chegada das malas e um esboço de planejamento do trabalho. A própria coordenadora reconhece que foi intermediária entre Maria e as demais professoras: "eu expliquei como era o projeto e tal". Portanto, o fato do projeto ter sido apresentado por uma pessoa que não esteve na reunião pode comprometer muito a recepção do acervo e a proposta de trabalhar com esse material a partir das "provocações" conceituais feitas pela equipe do programa educativo do CNFCP.

O exame desses dados iniciais indica alguns pontos relevantes para a compreensão dos possíveis problemas de comunicação entre as duas instituições: a professora Maria foi "provocada" a repensar alguns de seus conceitos a respeito do folclore e da cultura popular pelo fato de ter participado da reunião de apresentação dos projetos no CNFCP, em uma interação face a face, mas não teve oportunidade de compartilhar formalmente essa experiência com o grupo de professoras da escola. A coordenadora recebeu informações sobre essa reunião e elaborou reflexões pertinentes sobre os temas. Porém, assumiu integralmente a responsabilidade de repassar todas essas informações sobre o projeto, ao invés de proporcionar a Maria a oportunidade de compartilhar suas reflexões com as demais professoras.

O texto de apresentação do projeto, que acompanha o acervo, não foi um instrumento eficaz de "conversa com o professor" conforme a expectativa da equipe de educadores do CNFCP, já que $90 \%$ das professoras indicaram não ter lido o documento.A análise evidenciou alguns motivos que concorreram para isto: problemas estruturais das instituições envolvidas, problemas políticos na escola, falta de tempo e dificuldade de acesso às malas, por parte das professoras.

que faltou nas estratégias eleitas na prática comunicativa entre as duas instituições, neste estudo de caso? Uma resposta possível é dada pela própria Lucila Telles (2007), quando ela aponta para a necessidade de maior interação entre os representantes institucionais envolvidos nesse processo:

Lucila: Na verdade, quando as unidades começaram a circular, a gente fazia a avaliação nas escolas. Tinha lá uma conversa e tudo mais. Tinha uma conversa no início e outra no final. E depois, quando ele começou a multiplicar, e a equipe reduzir, isso ficou inviável. Então tem uma conversa antes e não tem uma conversa depois.

Autora I: Essa conversa antes é a reunião?

Lucila: É. E aí a gente tá ainda pensando em mexer nisso. Tem uma proposta da gente fazer a conversa depois. A gente sente falta disso.

(TELLES, 2007)

\section{Concepções de folclore e cultura popular}

No segmento da entrevista com Maria, destacado acima, essa professora expressa um alinhamento com a representante do CNFCP durante a conversa na reunião citada.Antes do encontro, ela achava que "o folclore era aquela prática antiga que as pessoas tinham o hábito de fazer e a cultura popular era $\circ$ que a gente fazia no dia a dia". É pertinente notar que a professora utiliza os verbos no passado (era, tinham, fazia, existia, achava) sinalizando que esse era o seu pensamento com relação a esses temas. Maria marca a modificação de sua percepção no presente com o advérbio de tempo "agora": "Agora eu já en- 
tendo que é a mesma coisa" e, quando a entrevistadora pergunta se alguma coisa provocou essa mudança, ela se refere à reunião e à "maneira" como foi dito: "justamente essa reunião, essa maneira que ela [representante do CNFCP] colocou [...] eu acho que mudou a minha ideia, né?". Nesse sentido houve uma ampliação conceitual, na medida em que Maria reconhece um processo de criação no qual podem ocorrer mudanças. $O$ folclore já não é mais algo que pode acabar, e sim algo que se transforma e se recria:"é uma coisa que você vai criando, né, não acaba”.

A Prof. ${ }^{a}$ Inês, responsável pela biblioteca da escola, também oferece, em seu discurso, algumas pistas de seu entendimento sobre folclore e cultura popular (SOUZA, 2007). Durante o período de empréstimo do acervo, que ficou alocado na biblioteca da escola, ela foi encarregada de mostrar e emprestar os livros do projeto "De mala e cuia" para as crianças. Em sua entrevista enuncia uma diferença entre as duas categorias; folclore está associado a lendas e mitos:"da ficção, da fantasia" e "a cultura popular é mais abrangente" já que "engloba" trabalhos manuais, esculturas e também histórias populares. Nesse sentido o folclore seria uma parte da cultura popular. Essa concepção foi determinante na seleção que a professora Inês fez sobre o acervo das malas. Como responsável pela biblioteca, Inês recebe, regularmente, turmas do Ensino Fundamental, lê histórias, faz empréstimos de livros, cuida do acervo e colabora nas pesquisas escolares. $O$ que nos chamou a atenção, na escolha da Prof. ${ }^{a}$ Inês, foi a predominância de lendas sobre todo o acervo das malas, - que corrobora com uma perspectiva a respeito do folclore que reitera concepções "tradicionais". A reincidência da temática das lendas é significativa, por parte dos profissionais observados, apesar de haver alguma variação quanto à técnica de produção: cartazes, textos, dobraduras, colagens e modelagens. As observações etnográficas corroboram com a reiteração de certas concepções na reprodução maciça de personagens como Saci, Curupira, lara e Mula-sem-cabeça.

Essas concepções, presentes no universo escolar observado, parecem ancorar uma tendência a eleger as lendas como representantes do folclore, circunscrevendo as possibilidades de leitura sobre a diversidade da cultura popular brasileira. Para Segala (2000, p. 66), na escola, "enfatiza-se a simples difusão de dados já compilados e 'didatizados', em detrimento da pesquisa, da descoberta, do uso das linguagens expressivas", resultando em um processo de cristalização, que transforma o folclore e a cultura popular em uma "compilação de curiosidades brasileiras, ideias avulsas, figurinhas sem nexo do boto cor de rosa, da lenda da vitória-régia, do bolo de milho, do Saci Pererê" (SEGALA, 2005, p. 108).

Um aspecto fundamental a ser destacado diz respeito à constatação de que a memória do folclore, na escola observada, traz traços marcantes da Campanha de Defesa do Folclore Brasileiro. Ao examinar, no conjunto de dados, as concepções sobre folclore e cultura popular, observamos uma forte tendência, entre os docentes, a eleger as lendas como representação simbólica do folclore. Nesses casos, em que foram produzidas associações do folclore e da cultura popular exclusivamente a lendas e a categorias tais como "antigo", “distante”,"“regional”,"não urbano”, "anônimo”, ou ainda, como algo que precisamos "resgatar" a fim de preservar nossa identidade nacional, percebemos que ocorre a reiteração conceitual. 
Se, por um lado, a análise dos dados sugere reiterações, ela também aponta para ampliações conceituais. Em muitas situações analisadas, notamos que as professoras produziram associações entre as categorias folclore/cultura popular e a atualidade, o cotidiano e a circularidade cultural, reconhecendo o caráter dinâmico da cultura como algo que construímos no nosso dia-a-dia e que está em permanente transformação. Nesses casos, mais alinhados com a perspectiva antropológica contemporânea, foi possível observar as crianças envolvidas na confecção de brinquedos (pipa, ioiô, dedoche, fantoche, peteca), na criação de mamulengos, no exercício da brincadeira com "pernas de pau" e "bilboquê" ou na pesquisa de ervas, chás, xaropes e outros produtos da medicina popular, presentes em seu cotidiano.

\section{Dando nó em pingo d'água}

Cabe ressaltar aqui que o caráter etnográfico da pesquisa possibilitou-nos testemunhar in loco o fato de que as ações educativas em instituições públicas são realizadas, muitas vezes, sob condições de trabalho adversas e, ainda, que os agentes sociais envolvidos nessas práticas enfrentam complexos problemas estruturais. No caso da escola municipal observada, o espaço físico inadequado, o elevado número de alunos por turma (entre 30 e 40), a remuneração precária dos profissionais de ensino do município do Rio de Janeiro, entre outros, são alguns exemplos do dia-a-dia daquela instituição escolar. No caso da instituição cultural, CNFCP, pudemos observar outras tantas dificuldades como a descontinuidade das políticas públicas, a escassez de verba, a interrupção de projetos, a redução das equipes e o número limitado de profissionais especializados. Consideramos louvável a iniciativa dos representantes institucionais entrevistados e contatados durante a pesquisa que, apesar de toda ordem de desafios, investem em projetos de parceria entre campos disciplinares distintos como museologia e educação. Reiteramos, portanto, as palavras de Santos (2008, p. 128):

[...] achei por bem lançar um olhar para além dos problemas cotidianos dos nossos museus e das nossas escolas, impregnados da burocracia que sufoca e da falta de estrutura para o desenvolvimento dos trabalhos. Não que os considere menos importantes. Ponderei que já estamos cansados de "bater na mesma tecla", causando até um certo esgotamento. Já levamos um bom tempo constatando, avaliando, chorando as nossas mágoas; agora, considero que é mais urgente do que nunca tomar como referencial os diagnósticos já realizados e, com o embasamento necessário, buscar outras estratégias de ação.

Uma vez que o CNFCP objetiva, entre outras propostas, introduzir nas escolas uma reflexão que amplie as noções de folclore e cultura popular, observar mudanças conceituais em curso em uma instituição escolar redimensiona a importância do programa educativo dessa instituição cultural.

Entretanto, para que o projeto enriqueça a pesquisa escolar, oferecendo amplo material para leitura e consulta, parece-nos fundamental refletir sobre a importância da mediação. É crucial que a preocupação com a democratização do acesso ao acervo cultural seja concomitante à preocupação com a qualificação da mediação do acervo disponibilizado. Na pesquisa aqui discutida, observamos que, por razões diversas, a exemplo da carência de profissio- 
nais na equipe da Difusão Cultural, responsável pelo programa educativo do CNFCP, o projeto "De mala e cuia" foi enviado à escola sem um mediador/ representante legitimado institucionalmente, favorecendo o uso apenas instrumental de seu material, em alguns casos.

Além disso, o acesso a outros acervos, como aqueles encontrados na biblioteca da escola e aos acervos pessoais das professoras, parece ter favorecido também o desinteresse pelo conteúdo do projeto. Questões conceituais não problematizadas parecem ter contribuído para a não diferenciação dos acervos disponíveis (das malas, da biblioteca e acervos pessoais).

Consideramos que os dados apontam para a constatação de que é necessário que o CNFCP invista em uma maior interação com as equipes escolares interessadas em fazer empréstimos dos projetos itinerantes, sobretudo no caso do "De mala e cuia". Para o alcance dos objetivos traçados, a atuação de um interlocutor - representante da instituição cultural - que dialogue com a escola, é de fundamental importância, mesmo que isso signifique menor expansão quantitativa dos projetos. Há que se ressaltar que a representante da escola que efetivamente participa da reunião no CNFCP tem uma oportunidade única de refletir, junto com a equipe do Programa Educativo, sobre as questões conceituais problematizadas nesse encontro. Contudo, muitas vezes, ela não é a profissional que desempenha o papel de mediadora na instituição escolar.

$\mathrm{Na}$ maior parte das interações analisadas, as pontes entre educação, cultura popular e o tema da pluralidade cultural brasileira não foram efetivadas. A palavra folclore ocupa um espaço, no imaginário da escola, atrelado a uma memória que tende a reproduzir estereótipos de Sacis e laras, e que não incorpora as ricas possibilidades de trabalho com a cultura popular. No entanto, reiteramos a abordagem que considera "fundamental a abertura das escolas para os saberes locais e expressões populares, instigando projetos de aprendizagem recíproca, de circularidade de saberes, recontextualizando e complexificando o processo de produção do conhecimento" (SEGALA, 2005, p. 108). A pesquisa corrobora com a "abertura das escolas para os saberes locais" como sendo um dos caminhos possíveis para o reconhecimento da diversidade cultural, o respeito à diferença e a problematização da pluralidade cultural brasileira no âmbito escolar.

A experiência de observação e reflexão sobre o programa educativo de uma instituição cultural nos fez perceber que há, subliminarmente, um jogo de forças e tensões entre os diferentes campos disciplinares envolvidos nessas práticas comunicativas. Os campos da Museologia, do Patrimônio, da Educação e da Arte-educação são campos de saberes distintos em disputa por poder e por espaço. Cada um deles tem seu próprio histórico de reflexões, debates e publicações sobre a função educativa dos museus, mas nem sempre essas experiências são compartilhadas. Um dos maiores desafios para a construção de um projeto interdisciplinar reside, exatamente, na criação de novas formas de conhecimento, a partir da transformação, baseada no diálogo, de práticas disciplinares com epistemologias diversas, uma necessidade crescente em nossa contemporaneidade. 


\section{Referências}

ABREU, Marta. Cultura popular: um conceito e várias histórias. In: ABREU, Marta; SOIHET, Rachel (Org.). Ensino de história: conceitos, temáticas e metodologia. Rio de Janeiro: Casa da Palavra, 2003.

CHAGAS, Mário. Museália. Rio de Janeiro: JC, 1996.

CHAGAS, Mário (Org.). Diabruras do Saci: museu, memória, educação e patrimônio. Musas - Revista Brasileira de Museus e Museologia, v. I, n. I, 2004.

CRETTON, Anamaria Aziz. Folclore, cultura popular e educação: discursos e memórias em práticas comunicativas institucionais. 2009. Dissertação (Mestrado em Memória Social)-UNIRIO, Rio de Janeiro, 2009.

DREW, Paul; HERITAGE, John. Talk at work. Oxford: Cambridge University Press, 1992.

GOFFMAN, Erving. Footing. In: RIBEIRO, Branca; GARCEZ, Pedro. Sociolingüística Interacional. São Paulo: Loyola, 2002. p. I07-I 48.

GOUVÊA, Guaracira; MARANDINO, Martha; LEAL, Maria Cristina. Educação e museu: a construção social do caráter educativo dos museus de ciência. Rio de Janeiro:Access, 2003.

LOPES, Maria Margareth. Bertha Lutz e a importância das relações de gênero, da educação e do público nas instituições museais. MUSAS - Revista Brasileira de Museus e Museologia, n. 2, p. 4I-47, 2006.

SANTOS, Maria Célia. Museu e educação: conceitos e métodos. In:

Encontros museológicos: reflexões sobre a museologia, a educação e o museu. Rio de Janeiro: MinC/IPHAN/DEMU, 2008. p. I25-I46.

SEGALA, Lygia. A troça, a traça e o forrobodó: folclore e cultura popular na escola. In: GARCIA, Regina Leite (Org.). Múltiplas linguagens na escola. São Paulo: DP\&A, 2000. p. 6I-75.

SEGALA, Lygia. Uma dinâmica de reinvenção das culturas populares. In: SEMINÁRIO DE POLÍTICAS PÚBLICAS PARA AS CULTURAS POPULARES, I., 2005, Brasília.Anais... Brasília: MinC, 2005. p. 107-109.

SILVA, Maria. Entrevista concedida a Ana Cretton. Rio de Janeiro, 19 out. 2007. SOUZA, Inês. Entrevista concedida a Ana Cretton. Rio de Janeiro, 01 nov. 2007.

STUDART, Denise Coelho.A produção intelectual do CECA-Brasil nas conferências internacionais do Comitê de Educação e Ação Cultural do ICOM de 1996 à 2004. MUSAS - Revista Brasileira de Museus e Museologia, v. I, n. I, p. 12-47, 2004.

TANNEN, Deborah;WALLAT, Cynthia. Enquadres interativos e esquemas de conhecimento em interação. In: RIBEIRO, Branca; GARCEZ, Pedro (Org.). Sociolingüística interacional. São Paulo: Loyola, 2002.

TELLES, Lucila. Entrevista concedida a Ana Cretton. Rio de Janeiro, 01 jul. 2007.

VILHENA, Luís Rodolfo da Paixão. Projeto e missão: o movimento folclórico brasileiro 1947-1964. Rio de Janeiro: Funarte/Fundação Getúlio Vargas, 1997. 